\title{
Economic Crisis and Corruption in the European Union
}

\author{
Mihaiela Ristei Gugiu \\ P. Cristian Gugiu
}

The Ohio State University

\begin{abstract}
Although significant attention has been paid to the impact of the recent economic crisis on European economies, less attention has been devoted to the association between the economic crisis and corruption. Utilizing structural equation modeling (SEM), the present study investigated the structural relationship between the economic crisis and perceptions of corruption in the European Union. Standard and multilevel SEM was used to estimate the relationship between the economic crisis and perceptions of corruption utilizing data from the 2011 Eurobarometer. The results confirmed the hypothesized model. Specifically, the study found a moderately strong direct positive relationship between the economic crisis and perceptions of corruption. The results indicated that a one-size-fits-all policy aimed at combating corruption, or perceptions thereof, is likely to yield inconsistent results.
\end{abstract}

Keywords: perceptions of corruption; economic crisis; structural equation modeling; European Union.

There is no doubt the recent economic crisis is the worst crisis the European countries have experienced since the Great Depression. According to the European Commission (2015), the economic recovery in the European Union (EU) continues to be slow due to incomplete macroeconomic adjustments and a sluggish pace of reform implementation. Although in 2014 the real Gross Domestic Product (GDP) grew by $0.3 \%$, EU member states continue to struggle with the aftermaths of the economic crisis (Eurostat, 2015a). The close ties between the European economies in the Eurozone have further exacerbated the problem, since these countries are intimately tied in terms of economic and fiscal policies. This not only makes it more difficult for a country to adopt measures that alleviate its economic situation, but any distinct action may adversely affect the economies of other Eurozone and EU members.

Additional concerns exist with regard to the increase of corruption in the EU. According to the European Commission (2011a), corruption is estimated to cost approximately $1 \%$ of EU GDP per annum, which is the equivalent of 120 billion euro. Various studies covering specific sectors of member states also found that the costs of corruption are prohibitive. For example, in 2008 the Italian Court of Auditors estimated the cost of corruption in the country at approximately 60 billion euro annually (Rizzo, 2010). A 2009 study in Greece estimated the cost of petty 
corruption at around 787 billion euro, an increase of 39 million euro since 2008 (Transpareny International Greece, 2009). Moreover, studies of corruption in the healthcare sector in 2009 estimated that corruption costs approximately 56 billion euro per annum within the EU (European Commission, 2011a). The seriousness of the problem prompted the European Commission (2011b) to act by establishing the EU Anticorruption Reporting Mechanism for Periodic Assessment, an instrument designed to harmonize the assessment of corruption and anticorruption strategies, and to facilitate the dissemination of successful practices among member states.

Although corruption has been given significant attention in the past couple of decades, the relationship between the recent economic crisis and corruption has been mostly limited to newspaper articles covering corruption scandals or calls for action based on assertions that a relationship exists between the two (see for example Transparency International's 2012 report on Corruption Risks in Europe). No attention, however, has been given to quantifying the association between the economic crisis and corruption from the perspective of the people who experience this relationship. Research has found that corruption tends to operate in environments where the formal rules of governing are being eroded or replaced by the informal rules of corruption (Ristei, 2010a). In times of crisis, opportunities for corruption to take place or expand are influenced by the ways in which governments respond to the crisis. During the recent economic crisis, the dominant European response was the adoption and implementation of austerity measures, which required significant reductions of the social programs provided by the national governments. This in turn, led to a deepening of poverty and its negative effects (McKee, Karanikolos, Belcher, \& Stuckler, 2012), to an increase in opportunities for corruption (Hunt, 2007; Ivlevs \& Hinks, 2013) and, in all likelihood, to a decline in people's trust in their governments. All these determinants are likely to have influenced how Europeans perceived the levels of corruption in their countries. Consistent with the literature, we hypothesized that the economic crisis would positively predict perceptions of corruption. Utilizing structural equation modeling (SEM), the present study examined the structural relationship between the economic crisis and respondents' perceptions of corruption using survey data from the 2011 Eurobarometer.

Examining the relationship between the economic crisis and perceptions of corruption is of theoretical and empirical significance. At a theoretical level, the study contributes to a better understanding of the factors that influence perceptions of corruption by focusing on the direct effect of a major economic crisis. At an empirical level, the study estimates the magnitude of the relationship between economic crisis and perceptions of corruption, which to date has been only speculated about. 
This, in turn, has policy implications by highlighting that anticorruption policies should be tied with policies designed to improve the state of EU's economies.

\section{The Impact of the Economic Crisis in EU}

By all accounts, the recent economic crisis severely impacted public deficit, government debt, unemployment, and poverty in the EU (European Commission, 2009). Since Fall 2008, government debt at the EU level continued to increase reaching 88.6\% of GDP in 2014 and 94.5\% in the Euro zone (European Commission, 2015). Public deficit also remains a salient issue despite slight improvement in 2014 (2.9\% of GDP) compared to its peak in 2009 ( $-6.9 \%$ of GDP) (Eurostat, 2015b). Furthermore, 12 EU members continue to have public deficits higher than the thresholds established by the "convergence criteria" that all members must meet to join the Eurozone. Under the Treaty on the European Union, EU member states (except Denmark and the United Kingdom) are required to "adopt the Euro and join the Euro area" (Economic and Financial Affairs, 2013). Hence, all EU member states are implicitly required to work towards lowering their government deficit to below $3 \%$ of GDP and government debt to below 60\% of GDP. Despite efforts to address the economic crisis, to date, five EU members (i.e., Greece, Ireland, Portugal, Spain and Cyprus) have required financial assistance (bailout) from the EU and IMF, with other countries potentially in need of assistance if their economies do not improve.

Not surprisingly, the impact of the crisis on the European population has been severe and unevenly distributed across the region. In 2009, the unemployment in Spain, Ireland, Portugal, Estonia, Lithuania, and Slovakia was in the double-digits (Eurostat, 2013a). In the following years, most EU countries continued to experience rising unemployment, which reached 12.1\% at the EU level in Spring 2013 (Eurostat, 2013b). Although the overall unemployment rate improved by summer of 2015 registering 9.5\% at EU level, some EU members continued to experience unemployment rates of more than 20\% (e.g., Greece, Spain). Additionally, the unemployment rate among young Europeans (under 25 years of age) continues to be a major problem. For example, in August 2015, the unemployment rate at the EU level was $20.4 \%$ with some members (e.g., Spain, Greece, Croatia, and Italy) registering unemployment rates higher than 40\% among its youth (Eurostat, 2015c). The growing unemployment rates meant that more people experienced a decline in their socioeconomic status due to the economic crisis. In 2013, the EU estimated that 122.6 million people (24.5\% of EU population) were "at risk of poverty or social exclusion," with $9.6 \%$ of its population being estimated as "severely 
materially deprived" or living in conditions seriously impacted by the lack of resources (Eurostat, 2015d).

\section{The Problem of Corruption}

Corruption is a complex phenomenon that has been the focus of numerous scholars and international organizations, including the World Bank, United Nation Development Programme, Organization for Economic Cooperation and Development, and EU. Throughout the years, numerous studies have shown corruption undermines good governance, the rule of law, and trust in institutions, thereby, de-legitimizing the democratic governance (Klitgaard, 1991; della Porta \& Vanucci, 1999; Rose-Ackerman, 1999; Karklins, 2005; Ristei, 2010b; Gugiu, 2012). Corruption was also found to adversely impact the allocation of public monies by encouraging unproductive public investments (projects with higher corruption capital) and under-investments in human capital by spending less on education (Mauro, 1995; Adaman \& Carkoglu, 2003; Krastev, 2004).

In a study examining the ability of public officials to exert bribes from private firms, Svensson (2003) found that firms are more likely to pay bribes when they interact with public officials whose actions affect their regular business operations. He also found that the amount of bribes demanded by public officials differs by type of public service provided and a firm's ability to pay the bribe or its power to refuse to pay it. The detrimental impact of corruption on the industrial competition and market structure was further confirmed by Emerson (2006), who found that government agents who are in a position to demand bribes from formal firms have a self-interest of demanding graft, which in turn further limits the number of firms able to compete on the market. In an environment of weak government regulations where public officials can exercise significant discretion, the costs for firms of doing business has the potential to become prohibitive and, thus further hinder competition (Breen \& Gillanders, 2012). Other studies also found that corruption "motivate[s] politicians and public servants to impose (or threaten to impose) market restrictions so as to maximize the resulting rents and bribes paid in connection with them" (Lambsdorff, 2007, p. 121), thereby self-perpetuating and further distorting the market competition and the distribution of benefits.

The negative impact of corruption on economic growth and trade have all been documented by various studies over the years (Mauro, 1995; Frye \& Shleifer, 1997; de Jong \& Bogmans, 2011). For example, Del Monte and Papagni (2007) examined the consequences of corruption in Italy and concluded that the corruption had serious negative effects on economic growth and led to significant costs for the business community. In a 
different study, Evrensel (2010) found that low corruption control and government effectiveness had a negative effect on growth volatility. His study also showed that corruption led to higher risk premiums and lower stock returns. Using a gravity model to estimate the effect of corruption on trade, Zelekha and Sharabi (2012) concluded that small changes in the level of corruption of a trading partner can have major consequences by damaging the trade flow in both directions. This is, in part, due to the fact that as corruption increases, the level of uncertainty in doing trade and, implicitly, the costs of trade increase.

The detrimental impact of corruption extends beyond the firms and businesses that compete on the market. Corruption has a very direct and significant effect on people's lives (Azfar \& Gurgur, 2008). Gupta and his colleagues (2002) examined the impact of corruption on income distribution and poverty by accounting for the effect of corruption on economic growth, tax system, social programs, asset ownership, and educational attainment. The authors found that an increase in the corruption index of a country by one standard deviation led to an increase in the GINI coefficient of income inequality by 11 points. Moreover, a one standard deviation increase in the growth rate of corruption was associated with a reduction in the income growth of poor people by $4.7 \%$ points per year. This was particularly relevant given the average income growth rate of 0.06 per year. In a separate study, Gyimah-Brempong (2002) concluded that corruption affects economic growth directly and indirectly by limiting investments on physical capital. He also found that a unit increase in corruption level led to a reduction of per capita income between 0.39 and 0.41 percentage points per year and that higher corruption was correlated with higher income inequality.

Finally, corruption was found to have a "regional contagion" effect making its containment more difficult in regions highly integrated socioeconomically (Becker, Egger, \& Seidel, 2009). Using a cross-sectional sample of 123 countries, Becker and his colleagues (2009) tested a spatial econometric model to assess the degree to which perceptions of corruption in one country are influenced by the levels of perceived corruption in other countries. The authors found that high levels of perceived corruption in one country led to an increase in the perception of corruption in the neighboring countries. Moreover, they concluded that countries that share similar cultures or language are more likely to be affected by this "contagion" effect, especially when an economic shock occurs. Not entirely surprising, the study found that perceptions of corruption travel longer distances and much faster than actual corrupt behaviors. Consequently, the spillover of corrupt behavior is smaller in magnitude and more limited geographically than perceptions of corruption. 


\section{Theoretical Considerations}

As previously discussed, there is an abundance of research supporting the existence of a link between economy and corruption at both perceived and actual level. Despite this evidence, the relationship between the recent economic crisis and corruption has not been rigorously investigated. In a recent assessment of anticorruption policies in Europe, Transparency International (2012) underscored the unethical practices favorable to the spread of corruption in the political and business communities, but failed to assess how the relationship between the economic crisis and corruption was felt by the people affected by this relationship. In a different study, Zaman and Ionescu (2014) developed a composite corruption index that purported to measure direct and indirect corruption in a country. The authors attributed the various country rankings to the economic crisis, but did not attempt to estimate the magnitude of the relationship between the economic crisis and corruption, particularly from the perspective of those directly affected by this association. Lastly, Ivlevs and Hinks (2013) investigated the impact of the economic crisis on corruption by focusing on the change in incidences of bribery in 30 countries in Central Eastern Europe and Central Asia. The authors found that the economic crisis had indirectly contributed to an increase in bribery; namely, individuals most affected by the economic crisis were also more likely to contact public officials and, therefore, were more likely to engage in corrupt transactions. Although revealing, the study excluded all developed countries from its analyses focusing exclusively on countries undergoing economic and political transitions.

The main hypothesis of this study is that the economic crisis had a direct positive relationship with perceptions of corruption. In other words, individuals in countries that experienced the worst of the economic crisis report more perceived corruption on the part of their governments. The recent EU Anti-Corruption Report (European Commission, 2014), highlighted the extent of corruption in the EU by focusing on both the costs incurred by EU member states as well as the increase in the perceived levels of corruption. Unlike Ivlevs and Hinks (2013), who found an increase in the incidence of bribery since the start of the economic crises, the European Commission estimated the actual incidences of corruption to be rare (1-3\%). However, the report found that the perceptions of corruption reached extremely high levels with three quarters of Europeans believing that corruption was a widespread problem in their own country. Furthermore, in countries most affected by the economic crisis (e.g., Greece, Italy, Spain, and the Czech Republic), the perceived levels of corruption were found to vary between 95\%-99\%. Although the association between economic crisis and corruption (or perceptions thereof) has been previously postulated based on case studies, 
no study has inferentially established this relationship at the country- or individual-level. The purpose of this study is to examine the structural links between economic crisis and perceptions of corruption.

Evidence from case studies suggests that perceptions of corruption may be attributed to the economic crisis and the scandals of corruption reported in the media. For example, in 2009, the head of the European Union's Judicial Cooperation Unit (Eurojust) was accused of improperly pressuring prosecutors to halt a corruption probe against the Spanish Prime Minister (Pop, 2009). In Fall 2011, a series of scandals were exposed in Austria highlighting the close ties between politics and business, which involved exchanges of millions of euros stuffed in plastic bags (Mayr, 2011). The series of scandals continued in 2012, when the Greek government was engulfed in allegations of corruption related to the now famous "Lagarde List," which contained the names of thousands of potential tax-evaders with Swiss bank accounts (Pangalos \& Stamouli, 2012). A few months later, a former defense minister along with 18 other high-ranking officials were accused of accepting about $\$ 210$ million in bribes (Kitsantonis, 2013), placing corruption once again on the first page of newspapers in Greece and abroad. Corruption scandals did not spare the royal family in Spain (Abend, 2013) or the Spanish Prime Minister (Hedgecoe, 2013), with the list of high-level corruption scandals extending to other EU members such as France, Slovenia, Czech Republic, and Bulgaria, to name only a few of the biggest scandals in recent years.

\section{Method}

\section{Data}

The present study utilized data from the Eurobarometer 76.1 administered in September 2011 (European Commission, 2011c). The survey included individuals from the 27 EU member states aged 15 years and older, who were selected using a multi-stage random probability sampling design. All national sample sizes were larger than 1,00o, except for three countries-Malta, Luxembourg, and Cyprus, which have smaller populations and correspondingly, smaller samples $(\sim 500)$. The total sample size for the EU region was 26,856. A total number of 35 items measured at the individual level (see Appendix) were included in the full SEM analysis along with two items measured at the country level (i.e., unemployment and public deficit).

The measurement of economic crisis included items on respondents' assessment of the impact of the crisis at the aggregate-level (world, European, national economy, and economic recovery) and individual-level (personal situation and paying bills), which were labeled economic impact. Data for EU members' 2011 unemployment and public deficit-the two 
national level items part of the economic crisis construct-were obtained from Eurostat (2013f) and were both measured on continuous scales. The perception of corruption construct was composed of items measuring individuals' perceived level of corruption at the national and institutional level, as well as their perception of the efforts made to fight corruption.

\section{Analytical Strategy}

A series of statistical and psychometric analyses were utilized to measure the association between the economic crisis and perceptions of corruption. First, ordinal parallel analysis and ordinal exploratory factor analysis (EFA) were used to explore the dimensionality of the survey. Second, Rasch modeling was used to transform the ordinal-scaled items into an interval-scaled composite score for each latent construct. This step was necessary because all the model fit statistics generated by SEM assume that data are measured with a continuous, interval scale. Third, multiple imputations were used to impute missing values based upon the pattern of responses across the latent constructs. In the penultimate step, multivariate outliers were removed to minimize bias in the SEM estimates. Finally, both the standard SEM and multilevel SEM were used to estimate the association between the economic crisis and perceptions of corruption.

Survey Dimensionality. A series of parallel analyses and EFAs were conducted-using SAS 9.4-to determine the number of factors to extract. Parallel Analysis is based on the idea that non-trivial factors should have eigenvalues larger than those derived from randomly generated data with an identical sample size and number of variables as the original data (Hayton, Allen, \& Scarpello, 2004). This method was amended by inputting a polychoric correlation matrix rather than using the raw data (Gugiu, Coryn, Clark, \& Kuehn, 2009; Gugiu, Coryn, \& Applegate, 2010), thereby accounting for the ordinal nature of the data. Ordinal EFA with promax rotation was then performed to ascertain the interpretability of the factor structure for each of the latent constructs (i.e., economic crisis, national corruption, institutional corruption, anticorruption strategies). Following conventional standards (Tabachnick \& Fidell, 2013), factors with less than 5 items and items with factor loadings less than 0.3 were deemed trivial and eliminated from the study.

Rasch Modeling. One of the chief limitations of the vast majority of survey research is its reliance on ordinal scales. It is well known that such measures cannot be meaningfully combined into composites without assuming equal distance between adjacent scale points (Gugiu, 2011; Stevens, 1946). Rasch modeling was employed to correct for this problem (Boone, Staver, \& Yale, 2014). As a result, the composite scores (person measures) have less measurement error than individual items (Crocker \& Algina, 1986). Moreover, Rasch modeling does not suffer from the 
problems associated with missing data. Hence, no imputation strategy was needed for this step. Item fit to the Rasch model was explored using the outfit statistics, point measure correlations, and exploration of the itemcategory figures for inverted thresholds (Linacre, 2002; Boone, Staver, \& Yale, 2014). Finally, so as to facilitate interpretation, items were re-scaled on a 0 to 100 scale, where low scores indicated low endorsement of the construct (e.g., the respondent perceived the level of corruption to be low) and high scores indicated high endorsement of the construct.

Multiple Data Imputation. Inspection of the data revealed that the rate of missing values per latent construct varied between $6.5 \%$ and $24 \%$. To avoid the bias produced by a listwise deletion, which would have retained only $51.4 \%$ of the 26,856 cases, we performed multiple imputations using SAS 9.4 PROC MI. The fully conditional specification method was employed due to the arbitrary missing pattern (SAS Institute, 2012a; van Buuren, 2007). Per recommendations in the field (Tabachnick \& Fidell, 2013), additional variables (e.g., respondent's age, gender, education) were entered into the model to improve its robustness. Ten imputations were used to estimate the missing values, thereby yielding approximately $97.5 \%$ of the variance attained by using an infinite number of imputations (Rubin, 1987; Yuan, 2010). Although standard practice calls for separate analyses of each imputed dataset prior to merging the results, examination of the 10 datasets revealed that the variability between the means, variances, and correlations to be extremely small, with a maximum difference of 0.009 for the means, 0.950 for the variances, and 0.017 for the correlations, and a root mean square error of 0.002 for the correlation coefficients across the 10 imputed datasets. Since SEM solely utilizes these three set of inputs, the differences between model parameters across the datasets would be trivial. Thus, the 10 imputed datasets were merged into a single dataset (via the mean operation for continuous data, the median for ordinal data, and the mode for nominal data).

Multivariate outliers. It is well-known that a single outlier can radically alter parameter estimates for continuous data. Consequently, outliers must be removed prior to performing analyses that assume linearity such as SEM. Since no single technique exists for identifying and eliminating outliers, a series of techniques were used to identify multivariate outliers-including Mahalanobis distance, studentized residuals, standardized DfFit, covariance ratio, and leverage-based on recommended standards (SAS Institute, 2012a; Tabachnick \& Fidell, 2013). A case was eliminated if it was flagged by any of the aforementioned techniques. In total, $3.8 \%$ of the data were removed, resulting in a final dataset of 25,834 respondents from 27 EU nations.

Structural Equation Modeling. To test the hypothesized relationships between economic crisis and corruption, both the standard 
structural equation model and the multilevel SEM were employed. Ideally, only the later method should have been necessary given that respondents were nested within nations. However, because two of the predictors (deficit and unemployment) were only measured at the national level, the multilevel model failed to converge. ${ }^{1}$ Hence, two models were run: the standard SEM which included all three exogenous (independent) indicators and a multilevel SEM which included only a single exogenous indicator measured at level-1. Moreover, a formative latent construct (analogous to a principal component) was estimated for economic crisis rather than one based on the common factor model because the definition of the economic crisis construct is generated from the indicators rather than the other way around. That is, it is not the case that a nation possesses a latent construct and on this basis alone it experiences or does not experience an economic crisis. Rather, the definition of economic crisis is a function of variability found in the set of indicators used to define the construct (known as a formative SEM) unlike a reflective or standard SEM in which the construct defines the indicators. Since all the indicators were measured by a continuous scale, the maximum likelihood (ML) estimation method was employed to determine how well the exogenous latent variable (economic crisis) predicted the endogenous (dependent) latent variable-perception of corruption. Furthermore, the asymptotic variance-covariance matrix was used to weight the input sample variance-covariance matrix (Schumacker \& Lomax, 2010) to account for the fact that Rasch measures are not normal. ${ }^{2}$

A series of model-fit statistics were used to assess the statistical significance of the theoretical model. A non-significant Satorra-Bentler scaled chi-square $\left(\mathrm{SB} \chi^{2}\right)$ value indicates that the theoretical model fits well the sample variance-covariance matrix (Brown, 2006). However, given the well-known sensitivity of the $\chi^{2}$ model-fit statistic to sample size (Brown, 2006; Schumacker \& Lomax, 2010), we relied more heavily on three other fit indices for assessing model fit: the root-mean-square error of approximation (RMSEA), standardized root-mean square residual (SRMR), and normed fit index (NFI). In the case of the first two indices,

\footnotetext{
1 Multilevel SEM is a relatively new statistical method. Presently, the analysis is constrained to variables measured at level-1 (individual), whose scores are then aggregated to create level-2 (nation) variables. Moreover, level-1 and level-2 models must be identical. The only permitted differences are for the parameter estimates (i.e., the values are allowed to differ between the two models). However, the inclusion of variables at one level but not the other level is not permitted. Since data for deficit and unemployment are only available at the national-level, the multilevel SEM model failed to converge. A similar result occurred when these variables were omitted from level-1 but retained for level-2.

2 The combination of ML and the asymptotic covariance matrix is commonly known as robust ML. It is the preferred method for handling continuous, non-normal data (Brown, 2006).
} 
values less than 0.05 are considered good, whereas for the NFI, values over 0.95 indicate a good fitting model (Schumacker \& Lomax, 2010).

\section{Results}

\section{Dimensionality of Survey Items}

According to the results of the Parallel Analysis and EFA, the economic impact construct was unidimensional. Inspection of the perception of corruption construct indicated the presence of a three factor structure. Accordingly, the three perception of corruption factors were labeled National Corruption, Institutional Corruption, and Anticorruption. Inspection of the model fit statistics produced by the Rasch model revealed that the 35 items adequately fit the model for their respective constructs.

\section{Structural Model}

Standard SEM. The hypothesized model examined whether the economic crisis (i.e., economic impact, unemployment, and public deficit) predicted perceptions of corruption. Figure 1 presents the completely standardized solution for the structural equation model. The goodness of fit indices-SB $\chi^{2}=138.13, d f=5, p<0.001, \mathrm{RMSEA}=0.032$ with a $90 \%$ confidence interval (CI) of (0.028, 0.037), SRMR $=0.013$, and NFI $=0.99-$ indicated the hypothesized model fit the sample data very well. Though not originally hypothesized, the error variances for Institutional Corruption and Anticorruption were allowed to correlate because upon further inspection of the items a method effect (Schumacker \& Lomax, 2010) was found to exist between the two constructs due to items which identified the same or related institutions (e.g., politicians, judiciary) for the two indicators. 3

As hypothesized, the greater the economic crisis, the higher the level of perceived corruption ( $\beta=0.53, p<0.05)$, which is a moderately large effect size (Cohen, 1988). Another way in which this relationship can be conceptualized is that nearly $30 \%$ of the variability in respondents' answers to the items pertaining to corruption was explained by the variability in their reports of how much the economic crisis had affected their lives and their nation. The effect of the economic crisis was greater

\footnotetext{
3 Recall that all the indicators, except for deficit and unemployment, represent Rasch measures (variables), which are generated by combining their associated survey items. Hence, if two Rasch measures contain items about similar institutions, it is likely that the ensuing Rasch variables will be more highly related with each other that with other variables that do not share this method effect, as was the case here.
} 
on perceptions of corruption at the national level $(\beta=0.46, p=0.01)$ than at the institutional level $(\beta=0.24, p<0.01)$ or on anticorruption strategies $(\beta=0.19, p<0.01)$.

Figure 1. Standard SEM with Standardized Coefficients

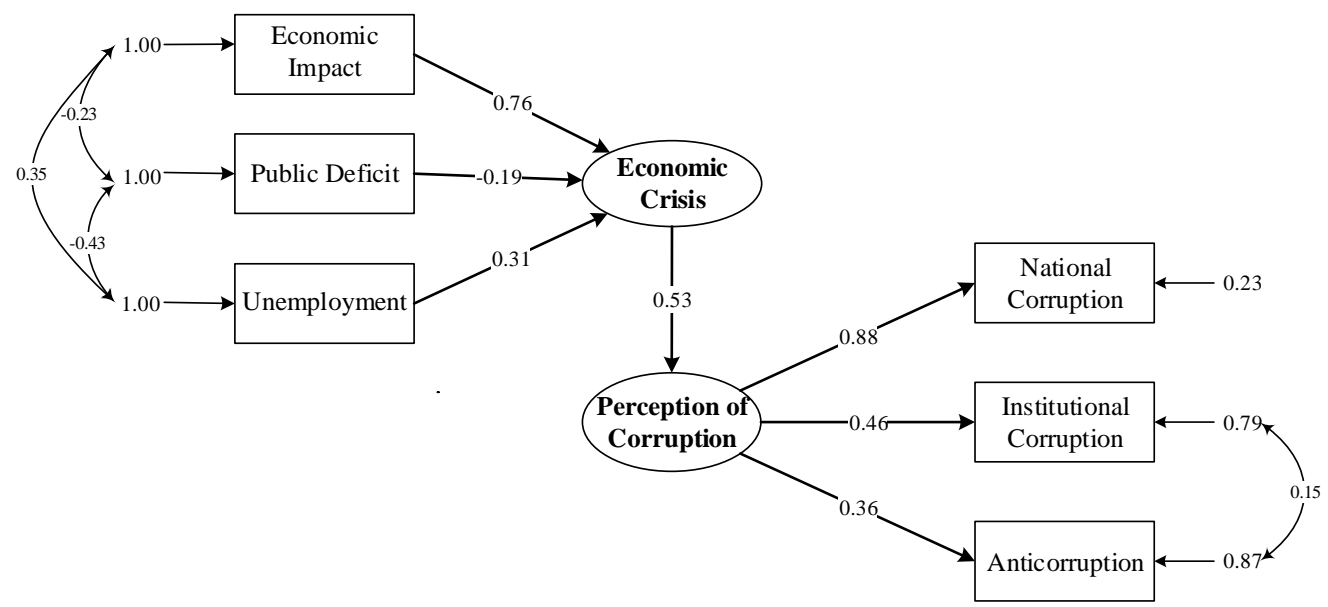

As hypothesized, the greater the economic crisis, the higher the level of perceived corruption ( $\beta=0.53, p<0.01)$, which is a moderately large effect size (Cohen, 1988). Another way in which this relationship can be conceptualized is that nearly $30 \%$ of the variability in respondents' answers to the items pertaining to corruption was explained by the variability in their reports of how much the economic crisis had affected their lives and their nation. The total effect of the economic crisis was greater on perceptions of corruption at the national level $(\beta=0.46$, $p=0.01)$ than at the institutional level $(\beta=0.24, p<0.01)$ or on anticorruption strategies $(\beta=0.19, p<0.01)$.

Multilevel SEM. The results for the multilevel SEM were similar to results reported above in that the economic crisis (sans unemployment, and public deficit) continued to predict perceptions of corruption. Figure 2 presents the completely standardized solution for the multilevel structural equation model. The goodness of fit indices $-\mathrm{SB} \chi^{2}=47.35, d f=7, p<0.001$, and RMSEA $=0.016$ with 90\% CI of (0.012, 0.021), SRMR $=0.008$, and NFI $=0.998$-indicated the hypothesized model fit the sample data very well. As hypothesized, the greater the economic crisis, the higher the level of perceived corruption $(\gamma=0.46, p<0.05)$, which accounts for slightly more than $20 \%$ of the variability in perceptions of corruption. Undoubtedly, the slightly lower estimate is attributable to the lost variability associated with public deficit and unemployment. As in the standard model, the effect of the economic crisis was greater on perceptions of corruption at the national level $(\beta=0.39, p=0.01)$ than at 
the institutional level $(\beta=0.22, p=0.01)$ or on anticorruption strategies ( $\beta$ $=0.15, p<0.01$ ).

Figure 2. Multilevel SEM with Standardized Coefficients

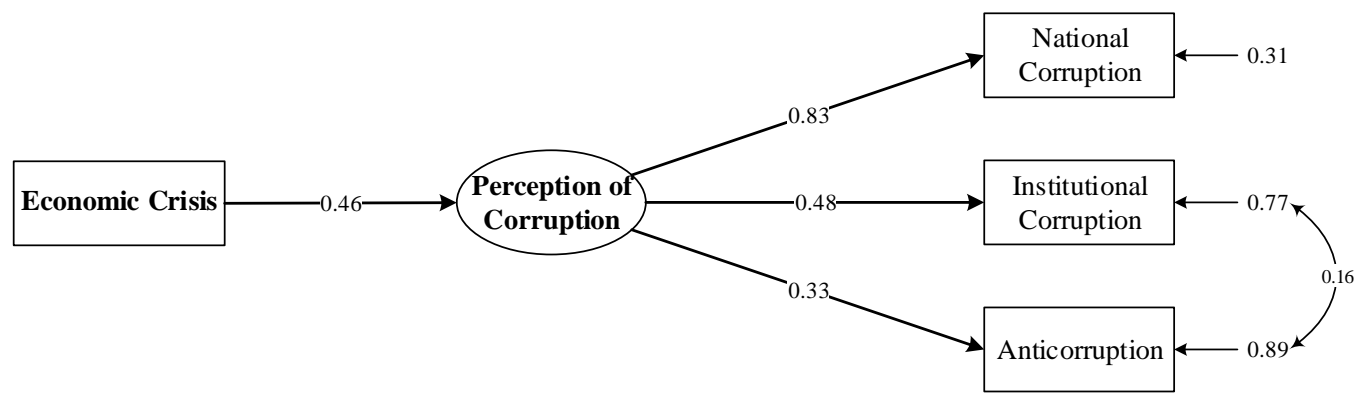

\section{Discussion}

The recent economic crisis has had a devastating effect on most of the European countries. While significant attention has focused on the impact of the crisis on the economy of the EU, including its member states and populations, less consideration has been given to the problem of corruption even though the EU recognizes it to be a highly salient and costly issue. The present study found a moderately strong direct positive relationship $(\beta=0.53)$ between the economic crisis and perceptions of corruption, which may explain the deterioration of the Corruption Perceptions Index (CPI) scores (Transparency International, 2011) for the EU members most affected by the economic crisis (e.g., Greece, Spain, Portugal). Additionally, the stronger impact of the economic crisis on the perceptions of corruption at the national level may be explained by the fact that for most people corruption may be a more salient issue at the broader national level. It may also be the case that the most notorious scandals of corruption reported in the media were focused on high level officials who most associate with their national government. Nonetheless, these results indicate that successfully addressing the impact of the crisis can result in a reduction in corruption, even if only at the perceptual level. Therefore, the success of economic and anticorruption policies-while distinct endeavors-is entwined. Moreover, given the existence of a "regional contagion" effect (Becker, Egger, \& Seidel, 2009), it is possible that successful anticorruption efforts in one state can spill-over in neighboring states. This scenario is even more likely given the EU effort to harmonize its anticorruption strategies and promote the dissemination of effective practices across all its member states.

As the current economic crisis abates, one expects the level of corruption, at least at the perceptual level, to also decline. Naturally, the 
decline can be accelerated by increasing anti-corruption strategies, whose impact on perceptions of corruption was almost on-par with that of the economic crisis based on its item-factor loading in the multilevel SEM. No doubt, then, policy measures that include avenues for investigating and prosecuting corrupt high-level officials will greatly reduce the public's perception of corruption, especially when coupled with an improving economy that may result in lower levels of unemployment and public deficit.

\section{Limitations of the Present Study}

Ideally, corruption should be investigated using objective measures given that studies have shown there are differences between perceived and experienced levels of corruption (Mocan, 2008; Dreher \& Schneider, 2010; Ristei, 2010a), the former being somewhat inflated. Nonetheless, in an experimental study of corruption focused on a railroad building project in Indonesia, Olken (2009) compared respondents' perceptions of corruption with an objective (i.e., "missing expenditure") measure of corruption. Although he found that perceptions of corruption tended to be biased (e.g., men reported more corruption than women), they were positively correlated with the objective measure of corruption. Moreover, respondents were able to distinguish between corruption related to a particular road project and general corruption. This led him to conclude that "biases in individual's views about corruption can lead to increased monitoring behavior, which may in turn reduce corruption" (Olken, 2009, p. 962). However, Olken's study focused on a small village in Indonesia and, by his own admission, the use of objective measures to assess corruption at a country or multi-country level would be extremely difficult, if at all possible.

To compound this problem, even objective measures of corruption may not adequately capture the construct. For example, the number of prosecutions or court cases of corruption may, in fact, measure judicial effectiveness rather than corruption. Furthermore, since corruption is an illegal activity for which compiling hard evidence is often very difficult, these measures may underestimate the actual level of corruption. The use of government expenditure may reflect public service incompetence rather than corruption and disentangling the two becomes itself a subjective process. Despite their clear weaknesses, perceptions of corruption are, nonetheless, important. Perceptions of corruption can be used to evaluate the success of anticorruption strategies implemented at national or supranational (EU) level, to identify areas that should be prioritized in their fight against corruption, and to evaluate progress (Kaufmann, Kraay, \& Mastruzzi, 2006; Gugiu M. R., 2012). Furthermore, high levels of perceived corruption were found to deter foreign investments (Treisman, 
2007), to discourage victims to report illegal activities to the police (Soares, 2004), and to even deter participation in the political process, such as voting (Morris, 2009). At a minimum, a high level of perceived corruption indicates that corruption is a salient problem and, in the absence of objective measures of corruption, perceptions remain the best available tool for large, and even small, studies.

Finally, despite their salience, the results of the present study are based on data collected at a single point in time. Arguably, a more comprehensive understanding of the relationship between economic crisis and perceptions of corruption, particularly with regard to change, would be obtained by using a longitudinal (preferably panel) study design. However, such designs require data to be collected at least at multiple points in time using the same measurement instrument. Unfortunately, although the EU has collected data on corruption prior to 2011, these surveys did not include questions assessing the economic crisis. Therefore, while the results found by this study are suggestive of a causal association between economic crisis and perceptions of corruption-given the unlikely event that perceptions of (or even actual) corruption precipitated the economic crisis throughout Europe-such a claim is not directly supported by the present study design. Rather, our data clearly support the existence of a strong association between economic crisis and perceptions of corruption.

\section{Final Remarks}

The present study demonstrated the significant relationship between the recent economic crisis in Europe and perceptions of corruption. Therefore, the EU economic crisis exhibited a moderately strong effect on corruption, at least at the perceptual level. The implications of these findings are that corruption can be combated not only by enacting and enforcing strong anticorruption policies but by mitigating the impact of economic crises. Hence, in addition to addressing the economic problems, the EU should incorporate in its anticorruption policy practices and measures which have been demonstrated to be successful at national or local level. Moreover, until a comprehensive policy is adopted and implemented at the EU level, an effort should be made to popularize effective anticorruption strategies in all EU member states and to highlight successful cases in the fight against corruption. A focus on the positive results in this fight coupled with the "regional contagion" effect is likely to positively contribute to this effort. Prosecution of corrupt EU officials will also strengthen the message the EU sends to all Europeans regarding its commitment to fight corruption at all levels and it will set an example for the member states to follow in their anticorruption effort. 


\section{ECONOMIC CRISIS AND CORRUPTION}

Author Notes. We would like to thank Gerhard Mels for feedback on an earlier version of our Lisrel syntax and the anonymous reviewers for their valuable suggestions.

\section{References}

Abend, L. (2013, February 25). Spain's Corruption Scandals: The Crisis of the Royal Family. Time.

Adaman, F., \& Carkoglu, A. (2003). Social Capital and Corruption during Times of Crisis: A Look at Turkish Firms during the Economic Crisis of 2001. Turkish Studies, 4, 120-145.

Azfar, O., \& Gurgur, T. (2008). Does Corruption Affect Health and Education Outcomes in the Philippines? Economics of Governance, 9, 197-244.

Becker, S. O., Egger, P. H., \& Seidel, T. (2009). Common Political Culture: Evidence on Regional Corruption Contagion. European Journal of Political Economy, 25, 300-310.

Boone, W. J., Staver, J. R., \& Yale, M. S. (2014). Rasch Analysis in the Human Sciences. New York: Springer.

Breen, M., \& Gillanders, R. (2012). Corruption, Institutions and Regulation. Economics of Governance, 13, 263-285.

Brown, T. A. (2006). Confirmatory Factor Analysis for Applied Research. New York : The Guilford Press.

Cohen, J. (1988). Statistical Power Analysis for the Behavioral Science (2nd ed.). New Jersey: Lawrence Erlbaum Associates.

Crocker, L., \& Algina, J. (1986). Introduction to Classical and Modern Test Theory. United States: Wadsworth Group/Thomson Learning.

de Jong, E., \& Bogmans, C. (2011). Does Corruption Discourage International Trade? European Journal of Political Economy , 27, 385-398.

Del Monte, A., \& Papagni, E. (2007). The Determinants of Corruption in Italy: Regional Panel Data Analysis. European Journal of Political Economy, 23, 379-396.

della Porta, D., \& Vanucci, A. (1999). Corrupt Exchanges: Actors, Resources, and Mechanisms of Political Corruption. New York: Aldine de Gruyter.

Dreher, A., \& Schneider, F. (2010). Corruption and the Shadow Economy: An Empirical Analysis. Public Choice, 144, 215-238.

Economic and Financial Affairs. (2013, Auguts 5). Retrieved August 6, 2013, from European Commission: http://ec.europa.eu/economy_finance/euro/adoption/who_can_join/

Emerson, P. M. (2006). Corruption, Competition, and Democracy. Journal of Development Economics, 81, 193-212.

European Commission. (2009). Economic Crisis in Europe: Causes, Consequences and Responses. Luxembourg: Office for Offcial Publications of the European Communities. doi:10.2765/84540

European Commission. (2011a). Impact Assessment. Brussels: European Commission. 
European Commission. (2011b). Commision Decision Establishing an EU AntiCorruption Reporting Mechanism for Periodic Assessment. Brussels: European Commission.

European Commission. (2011c, September). Eurobarometer 76.1. Cologne: GESIS. doi:10.4232/1.11695

European Commission. (2014). EU Anti-Corruption Report. Brussels: European Commission.

European Commission. (2015). European Economic Forecast: Winter 2015. Brussels: European Commission. Retrieved October 23, 2014, from http://ec.europa.eu/economy_finance/publications/european_economy/201 4/pdf/ee2_en.pdf

Eurostat. (2013a, July 31). Unemployment Statistics. Retrieved August 8, 2013, from http://epp.eurostat.ec.europa.eu/statistics_explained/index.php/Unemploy ment_statistics

Eurostat. (2013b, June 14). Harmonised Unemployment Rate by Sex. Retrieved August 7, 2013, from http://epp.eurostat.ec.europa.eu/tgm/table.do?tab=table\&language=en\&pco $\mathrm{de}=$ teilmo2o\&tableSelection $=1 \&$ plugin $=1$

Eurostat. (2013f). Government Statistics. Retrieved July 29, 2013, from Eurostat: http://epp.eurostat.ec.europa.eu/portal/page/portal/government_finance_s tatistics/data/database

Eurostat. (2015a, February 13). Newsrelease Indicators. Eurostat Newsrealease Indicators.

Eurostat. (2015b, April 21). Provision of deficit and debt data for 2014. News Release Euroindicators.

Eurostat. (2015c, September 30). Euro area unemployment rate at $11 \%$. News Release Euroindicators.

Eurostat. (2015d, January). People at Risk of Poverty or Social Exclusion. Retrieved November 29, 2015, from Eurostat: http://ec.europa.eu/eurostat/statistics-

explained/index.php/People_at_risk_of_poverty_or_social_exclusion

Frye, T., \& Shleifer, A. (1997). The Invisible Hand and The Grabbing Hand. American Economic Review, 87, 354-358.

Gugiu, M. R. (2012). EU Enlargement and Anticorruption: Lessons Learned from Romania. Journal of European Integration, 34, 429-446.

Gugiu, P. C. (2011). Summative Confidence. Ann Arbor, MI: ProQuest Dissertations \& Theses.

Gugiu, P. C., Coryn, C., \& Applegate, B. (2010). Structure and measurement properties of the Patient Assessment of Chronic Illness Care instrument. Journal of Evaluation in Clinical Practice, 16, 509-516.

Gugiu, P. C., Coryn, C., Clark, R., \& Kuehn, A. (2009). Development and Evaluation of the Short Version of the Patient Assessment of Chronic Illness Care Instrument. Chronic Ilness, 5, 268-276.

Gupta, S., Davood, I. H., \& Alsonso-Terme, R. (2002). Does Corruption Affect Income Inequality and Poverty? Economics of Governance, 3, 23-45.

Gyimah-Brempong, K. (2002). Corruption, Economic Growth and Income Inequality in Africa. Economics of Governance, 3, 183-209. 


\section{ECONOMIC CRISIS AND CORRUPTION}

Hayton, J. C., Allen, D. G., \& Scarpello, V. (2004). Factor Retention Decisions in Exploratory Factor Analysis: a Tutorial on Parallel Analysis. Organizational Research Methods, 7, 191-205.

Hedgecoe, G. (2013, July 10). Spanish corruption scandal threatens to unseat prime minister Mariano Rajoy. Time.

Hunt, J. (2007). How Corruption Hits People When They Are Down. Journal of Development Economics, 84, 574-589.

Ivlevs, A., \& Hinks, T. (2013). Global Economic Crisis and Corruption Experience: Evidence from Transition Economies. Bristol, UK: University of the West of England.

Karklins, R. (2005). The System Made Me Do It: Corruption in Post-Communist societies . New York: M.E. Sharpe, Inc.

Kaufmann, D., Kraay, A., \& Mastruzzi, M. (2006, December). Measuring Corruption: Myths and Realities. The World Bank. Retrieved August 10, 2013, from http://www1.worldbank.org/publicsector/anticorrupt/corecourse2007/ Myths.pdf

Kitsantonis, N. (2013, April 23). Greek Ex-Minister Is Tried in Bribery Cover-Up Case. The New York Times, p. A8.

Klitgaard, R. (1991). Controlling Corruption. Los Angeles: University of California Press.

Krastev, I. (2004). Shifting Obsession: Three Essays on the Politics of Anticorruption. New York: Central European University Press.

Lambsdorff, J. G. (2007). The Institutional Economics of Corruption and Reform: Theory, Evidence, and Policy. Cambridge: Cambridge University Press.

Linacre, M. J. (2002). What do Infit and Outfit, Mean-square and Standardized mean? Rasch Measurement Transactions, 16, 878.

Mauro, P. (1995). Corruption and Growth. The Quarterly Journal of Economics, $110,681-712$.

Mayr, W. (2011, October 13). Corruption Scandals in Austria: A Web of Sleaze in Elegant Vienna. Spiegel International.

McKee, M., Karanikolos, M., Belcher, P., \& Stuckler, D. (2012). Austerity: a failed experiment on the people of Europe. Clinical Medicine, 12, 346-350.

Mocan, N. (2008). What Determines Corruption? International Evidence From Microdata. Economic Inquiry, 46, 493-510.

Morris, S. D. (2009). Corruption and democracy at the state level in Mexico. In C. H. Blake, \& S. D. Morris, Corruption and Democracy in Latin America (pp. 169-192). Pittsburgh: University of Pittsburgh Press.

Olken, B. A. (2009). Corruption Perceptions vs. Corruption Reality. Journal of Public Economics, 93, 950-964.

Pangalos, P., \& Stamouli, N. (2012, December 29). Scandal Deepens Over Greece's 'Lagarde List'. The Wall Street Journal.

Pop, V. (2009, May 13). Eurojust Chief Embroiled in Portuguese Corruption Scandal. EUobserver.com.

Ristei, M. (2010a). Competing Formal and Informal Institutions in a Democratizing Setting: An Instiutional Analysis of Corruption in Romania. Ann Arbor, Michigan: ProQuest Dissertations and Theses. 
Ristei, M. (2010b). Politics of Corruption: Political Will and The Rule of Law in Post-Communist Romania. Journal of Communist Studies and Transition Politics, 26, 341-362.

Rizzo, S. (2010, May 6). Alle Radici Della Corruzione [At the Roots of Corruption]. Corriere dela Serra. Retrieved from http://www.corriere.it/ editoriali/10_maggio_06/radici_corruzione_62563380-58cd-11df-ace4oo144fo2aabe.shtml

Rose-Ackerman, S. (1999). Corruption and Government: Causes, Consequences and Reform. Cambridge: Cambridge University Press.

Rubin, D. B. (1987). Multiple Imputation for Nonresponse in Surveys. New York: John Wiley \& Sons, Inc.

SAS Institute. (2012a). Multiple Imputation for Missing Data. Retrieved January 28, 2012, from SAS: http://support.sas.com/rnd/app/da/new/dami.html

Schumacker, R. E., \& Lomax, R. G. (2010). A Beginner's Guide to Structural Equation Modeling (3rd ed.). New York: Taylor \& Francis Group, LLC.

Soares, R. R. (2004). Crime reporting as a measure of institutional development. Economic Development and Cultural Change, 52, 851-871.

Stevens, S. S. (1946). On the Theory of Scales of Measurement. Science, 103, 677680 .

Svensson, J. (2003). Who Must Pay Bribes and How Much? Evidence From a Cross Section of Firms. Quarterly Journal of Economics, 118, 207-230.

Tabachnick, B. G., \& Fidell, L. S. (2013). Using Multivariate Statistics. Upper Saddle River, NJ: Pearson Education, Inc.

Transparency International. (2011). Corruption Perceptions Index 2011. Retrieved September 21, 2013, from Transparency International: The Global Coalition Against Corruption: http://www.transparency.org/cpi2011/ results\#CountryResults

Transparency International. (2012). Money, Politics, Power: Corruption Risks in Europe. Berlin: Transparency International.

Transpareny International Greece. (2009). National Survey Corruption in Greece. Retrieved August 9, 2013, from Transparency International Greece: http://en.transparency.gr/Content.aspx?page $=48$

Treisman, D. (2007). What have we learned about the causes of corruption from ten years of cross-national empirical research? Annual Review of Political Science, $10,211-244$.

van Buuren, S. (2007). Multiple Imputation of Discrete and Continuous Data by Fully Conditional Specification. Statistical Methods in Medical Research, 16, 219-242.

Yuan, Y. C. (2010). Multiple Imputation for Missing Data: Concepts and New Development (Version 9.0). Rockville, MD: SAS Institute Inc.

Zaman, G., \& Ionescu, L. (2014). The Impact of International Economic Crisis on Corruption in Romania. Economic Computation \& Economic Cybernetics Studies \& Research, 48, 1-17.

Zelekha, Y., \& Sharabi, E. (2012). Corruption, Institutions and Trade. Economics of Governance, 13, 169-192. 


\section{Appendix: Eurobarometer 76.1 (September 2011)}

\section{Economic Crisis}

\section{Economic Impact}

QA14: To what extent do you consider that the current crisis is or is not having an impact on each of the following?

QA1_1: The world economy.

QA1_2: The European economy.

QA1_3: The (Nationality) economy.

QA1_4: Your personal situation.

Scale $1=$ Very significant impact; $2=$ Fairly significant impact; $3=$ Not really any impact; $4=$ No Impact at all. ${ }^{5}$

QA2: Here are some situations that could have arisen recently in your working life or in the working life of those around you. For each of them, please tell me if this has happened as a direct consequence of the crisis, if it has happened but was not a direct consequence of the crisis, or it has not happened at all.

QA2_1: You have lost your job/your partner (husband or wife, partner, etc.) has lost his/her job.

QA2_2: One of your relatives has lost his/her job.

QA2_3: One of your colleagues has lost his/her job.

QA2_4: Someone you know who is neither related to your not a colleague has lost his/her job.

Scale: $1=$ Yes, as a direct consequence of the crisis; $2=$ Yes, but not as a direct consequence of the crisis; $3=\mathrm{No}$, it has not happened at all. ${ }^{6}$

QA4: When it comes to a return to growth in (our country), which one of the following opinions is closest to your own?

Scale: $1=$ We are already returning to growth; $2=$ A return to growth will start in the coming months; $3=$ A return to growth will start in the coming years; $4=$ The crisis is going to last for many years.

D6o: During the last twelve months, would you say you had difficulties to pay your bills at the end of the month..?

Scale: $1=$ Most of the time; $2=$ From time to time; $3=$ Almost never/never.

Unemployment: percentage unemployment rate at the country-level (range 4.2 to 21.7 with smaller values denoting lower unemployment rates).

4 Item numbers reflect the codes assigned by the European Commission in the original survey.

5 The scale was reversed so that high scores indicate high impact and low scores low impact. All DK, "Refuse to Answer," or "Not applicable" options were set to missing for all variables analyzed.

${ }^{6}$ Categories 1 and 2 were merged so as to create a dichotomous variable. 
Public Deficit: percentage of GDP at the country-level (range -13.4 to 4.3 , with negative values denoting higher deficits).

\section{Perception of Corruption}

\section{Perception of Corruption at the National Level (i.e., National Corruption)}

QC1: For each of the following statements, could you please tell me whether you totally agree, tend to agree, tend to disagree or totally disagree with it.

QC1_1: Corruption is a major problem in (our country).

QC1_2: There is corruption in local institutions in (our country).

QC1_3: There is corruption in regional institutions in (our country).

QC1_4: There is corruption in national institutions in (our country).

QC1_6: Corruption is part of the business culture in (our country).

QC1_7: Corruption is more widespread in (our country) than in other EU member states.

QC1_8: You are personally affected by corruption in your daily life.

Scale: $1=$ Totally agree; $2=$ Tend to agree; $3=$ Tend to disagree; $4=$ Totally disagree. ${ }^{7}$

\section{Perception of Corruption in Specific Sectors (i.e., Institutional Corruption)}

QC4: In (our country), do you think that the giving and taking of bribes, and the abuse of positions of power for personal gain, are widespread among any of the following?

QC4_1: People working in the police sector.

QC4_2: People working in the customs services.

QC4_3: People working in the judicial services.

QC4_4: Politicians at national level.

QC4_5: Politicians at regional level.

QC4_6: Politicians at local level.

QC4_7: Officials awarding public tenders.

QC4_8: Officials issuing building permits.

QC4_9: Officials issuing business permits.

QC4_10: People working in the public health sector.

QC4_11: People working in the public education sector.

QC4_12: Inspectors (health, construction, food quality, sanitary control and licensing).

Scale: $1=$ Yes; $0=$ No.

7 The scale was reversed so that high scores indicate high perceptions of corruption and low scores indicate low perceptions of corruption. 


\section{Perception of the Effectiveness of Anticorruption Policies (i.e., Anticorruption)}

QC7: For each of the following statements, could you please tell me whether you totally agree, tend to agree, tend to disagree, or totally disagree.

QC7_1: (Nationality) Government efforts to combat corruption are effective.QC7_2: There are enough successful prosecutions in (our country) to deter people from giving or receiving bribes.

QC7_4: There is sufficient transparency and supervision of the financing of political parties in (our country).

QC7_5: EU helps in reducing corruption in (our country).

Scale: $1=$ Totally agree; Tend to agree; $3=$ Tend to disagree; $4=$ Totally disagree. 